\begin{tabular}{c} 
International Journal of Engineering \& Technology, $7(4)(2018) 3654-3661$ \\
International Journal of Engineering \& Technology \\
SPC \\
$\begin{array}{c}\text { Website: } \text { www.sciencepubco.com/index.php/IJET } \\
\text { doi: } 10.14419 / \text { ijet.v7it.20606 } \\
\text { Research paper }\end{array}$ \\
\hline
\end{tabular}

\title{
Comparative study of prim and genetic algorithms in minimum spanning tree and travelling salesman problem
}

\author{
Andysah Putera Utama Siahaan ${ }^{1}$ *, Zulfi Azhar ${ }^{2}$, M. D. L. Siahaan ${ }^{1}$, Muhammad Iqbal ${ }^{1}$, Zuhri Ramadhan ${ }^{1}$ \\ Wirda Fitriani $^{1}$, Zulham Sitorus ${ }^{1}$, Nova Mayasari ${ }^{1}$, Indri Sulistianingsih ${ }^{1}$, Dedi Purwanto ${ }^{1}$, R. F. Wijaya ${ }^{1}$, \\ Heri Kurniawan $^{1}$, Rio Septian Hardinata ${ }^{1}$, Muslim Muslim ${ }^{1}$, Ressy Dwitias Sari ${ }^{1}$, \\ Mhd. Furqan ${ }^{3}$, Ali Ikhwan ${ }^{3}$, Muhammad Khahfi Zuhanda ${ }^{4}$, A. H. Lubis ${ }^{4}$, \\ Phak Len Eh Kan ${ }^{5}$, K. N. F. K. Azir ${ }^{5}$ \\ ${ }^{1}$ Faculty of Science and Technology, Universitas Pembangunan Panca Budi, Medan, Indonesia \\ ${ }^{2}$ Department of Information System, STMIK Royal Kisaran, Kisaran, Indonesia \\ ${ }^{3}$ Department of Computer Science, Universitas Islam Negeri Sumatera Utara, Medan, Indonesia \\ ${ }^{4}$ Faculty of Engineering, Universitas Medan Area, Medan, Indonesia \\ ${ }^{5}$ School of Computer and Communication Engineering, Universiti Malaysia Perlis, Pauh, Malaysia \\ *Corresponding author E-mail: andiesiahaan@gmail.com
}

\begin{abstract}
Optimization is the essential thing in an algorithm. It can save the operational cost of an activity. At the Minimum Spanning Tree, the goal to be achieved is how all nodes are connected with the smallest weights. Several algorithms can calculate the use of wei ghts in this graph. Genetic and Primary algorithms are two very popular algorithms for optimization. Prim calculates the weights based on the shortest distance from a graph. This algorithm eliminates the connected loop to minimize circuit. The nature of this algorithm is to trace all nodes to the smallest weights on a given graph. The genetic algorithm works by determining the random value as first initialization. This algorithm will perform selection, crossover, and mutation by the number of rounds specified. It is possible that this algorithm can not achieve the maximum value. The nature of the genetic algorithm is to work with probability. The results obtained are the most optimal results according to this algorithm. The results of this study indicate that the Prim is better than Genetics in determining the weights at the minimum spanning tree while Genetic algorithm is better for travelling salesman problem. Genetics will have maximum results when using large numbers of rotations and populations.
\end{abstract}

Keywords: Prim; Genetic Algorithm; Minimum Spanning Tree; Artificial Intelligent.

\section{Introduction}

Electricity is a significant resource [1]-[4] in the use of electronic devces. Speed and security are the essential things in the delivery of digital information [5]-[11]. Minimum spanning tree is a tree that connects between nodes of the result of minimizing the weights present in a complete graph. A graph is a mathematical representation of a fact that is related to distance [12]-[14]. This tree can be defined with a weighted graph. Directed graphs and non-directional graphs are subgraphs that each node is connected to one another. A graph can produce multiple ranges that have different weights [15]-[17] The smallest weights are the minimum spanning tree. The more branching in the tree, the more the different ranges. Weighting is done by choosing the smallest weights on each edge [18]-[20]. Each weight will be compared with the other weights that lead to the next node. The smallest weight is the most significant chance of choosing the next node. The minimum use of spanning tree is mostly done in real life. It is related to the cost of raw materials used to build a communication network. For example, to install fiber optic cables between buildings or cities requires proper optimization to avoid excessive use of cables
[21]-[23]. If there are savings made in cable purchases, the budget used for the project is getting smaller. The economic principle says, the less material used, the less financial expenditure [24][32]. The following figure explains why a minimum spanning tree is required.

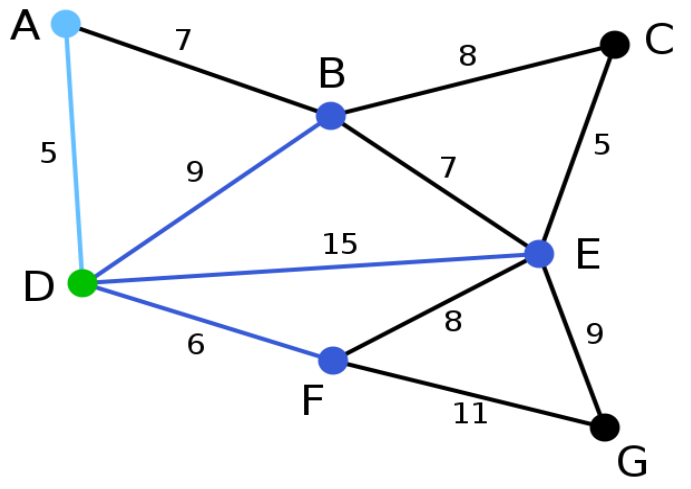

Fig. 1: Multiple Possible Spans. 
Some opportunities can be made to connect "A" to "G." Several circuits occur in graph form in figure 1 [33]. In the simple graph, weights can be calculated manually. However, on a graph with a huge number of nodes, weights must be calculated by the computer. Genetic and Prim Algorithms can calculate the optimal weight used in a graph. Both of these algorithms have different techniques. The genetic algorithm uses a probability system to increase the minimum weight prediction while the Prim refers to the backtracking system on the minimum weight search [34]-[36] The occurrence of backtracking due to a final condition is not fulfilled [37]. This study tries to compare the performance of both algorithms to see which algorithm is better to determine the minimum spanning tree in a graph.

\section{Related works}

\subsection{Yumnah research}

Yumnah conducted this research as a computer science thesis This research is about Knapsack problem using the genetic algorithm. Genetic algorithms can optimize the needs based on the constrained weights [38][39]. In the Knapsack problem, not al nodes can be explored. Successfully visited nodes must match the specified criteria. Knapsack Problem has an essential role in limiting the number of nodes that must be neglected in the case of Travelling Salesman Problem. All nodes will be explored to get the most optimal value for a given generation. Knapsack is applied at least have two parameters to run correctly. Knapsack has two parameters, the number of nodes and the distance weight [40]. Optimization is done by calculating the distance weights to have the same value with the value of the proposed solution. The number of nodes affects how many coordinate points are visited. The optimal value of this problem depends on the technique performed on the mutation process. The dynamic mutation method aims to determine the value of mutation rate in each population [41][42]. The state of the population in each generation will affect the outcome of the genetic process. The author said that technique would approach the results of a generation approaching completion [43].

Population taking is determined on a sustained basis at this point Testing is done by taking 30 nodes as a weighted graph form as shown in Figure 2. Knapsack problem will take ten nodes to be optimized with specific weights. Target is a goal that will be achieved in Knapsack problem. The fundamental difference to Knapsack is that nodes are captured not all of the existing nodes are different from the travelling salesman problem model. The number of nodes in Knapsack is determined based on the input weight. In a travelling salesman problem, all created nodes must be visited and returned to the initial node. Minimal distance is the optimal result obtained by using the genetic algorithm. The author tries to test ten nodes with weights of 400 .

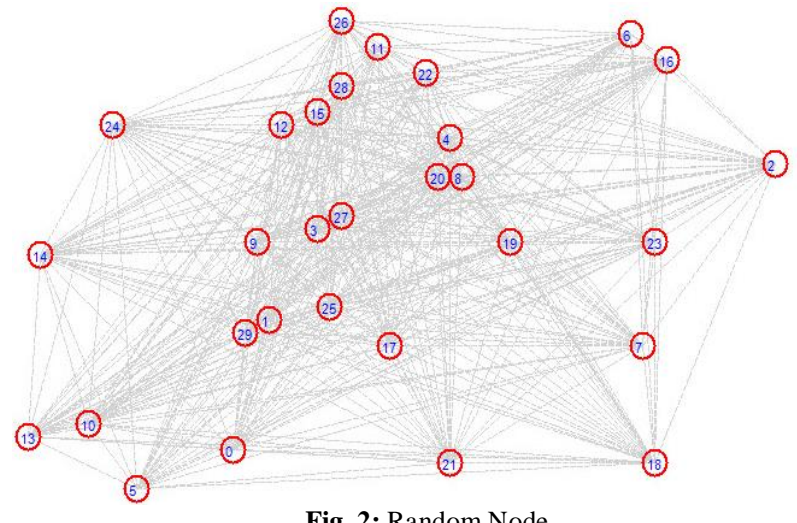

Fig. 2: Random Node.

Coordinate creation should not have the same value on the $\mathrm{X}$-axis and the $\mathrm{Y}$-axis at the same time. There should be no exact coordinates of value. Problems encountered if two nodes have the same coordinates is no movement on the nodes. However, this has a tiny chance because the generated value is a random value. If multiple nodes have the same value on either $\mathrm{X}$ axis or $\mathrm{Y}$ axis, it will not affect the process of Knapsack calculation [44].

Table 1: Random Populations

\begin{tabular}{lllllllllll}
\hline Populartio & $\mathrm{N}$ & $\mathrm{N}$ & $\mathrm{N}$ & $\mathrm{N}$ & $\mathrm{N}$ & $\mathrm{N}$ & $\mathrm{N}$ & $\mathrm{N}$ & $\mathrm{N}$ & $\mathrm{N} 1$ \\
$\mathrm{n}$ & 1 & 2 & 3 & 4 & 5 & 6 & 7 & 8 & 9 & 0 \\
\hline 0 & 22 & 8 & 12 & 4 & 13 & 3 & 14 & 11 & 26 & 10 \\
1 & 4 & 29 & 0 & 18 & 22 & 26 & 12 & 14 & 23 & 27 \\
2 & 1 & 4 & 22 & 16 & 10 & 8 & 19 & 6 & 20 & 28 \\
3 & 19 & 16 & 1 & 27 & 13 & 14 & 9 & 21 & 8 & 7 \\
4 & 24 & 7 & 4 & 26 & 15 & 16 & 3 & 1 & 20 & 17 \\
5 & 15 & 28 & 21 & 8 & 18 & 19 & 14 & 25 & 24 & 3 \\
6 & 15 & 5 & 23 & 27 & 19 & 16 & 28 & 3 & 2 & 8 \\
7 & 15 & 24 & 3 & 14 & 2 & 25 & 28 & 26 & 0 & 21 \\
8 & 3 & 16 & 15 & 2 & 12 & 23 & 26 & 21 & 7 & 25 \\
9 & 28 & 14 & 23 & 5 & 21 & 17 & 12 & 7 & 3 & 27 \\
\hline
\end{tabular}

Table 1 describes the formation of 10 generated populations obtained from the population generation process. Population from population 0 to 9 will be calculated for getting fitness value. Fitness that approaches the target has a greater chance to be a parent in the selection and mutation process.

Table 2 describes the calculation of ten generations produces the best value of Fitness $=1$ where the target is obtained according to the desired target. The population that has the value of Fitness $=1$ there are three among others Population [0], Population [5] and Population [8]. Trajectory in this population is as follows: $22-7-19-16-23-2-8-24-18-11-22$

Table 2: Genetic Algorithm Result

\begin{tabular}{lllllllllll}
\hline Populatio & $\mathrm{N}$ & $\mathrm{N}$ & $\mathrm{N}$ & $\mathrm{N}$ & $\mathrm{N}$ & $\mathrm{N}$ & $\mathrm{N}$ & $\mathrm{N}$ & $\mathrm{N}$ & $\mathrm{N} 1$ \\
$\mathrm{n}$ & 1 & 2 & 3 & 4 & 5 & 6 & 7 & 8 & 9 & 0 \\
\hline 0 & 22 & 7 & 19 & 16 & 23 & 2 & 8 & 24 & 18 & 11 \\
1 & 18 & 19 & 2 & 8 & 23 & 24 & 11 & 16 & 22 & 7 \\
2 & 24 & 23 & 8 & 19 & 2 & 22 & 7 & 11 & 16 & 18 \\
3 & 8 & 7 & 11 & 23 & 22 & 16 & 18 & 24 & 19 & 2 \\
4 & 23 & 18 & 16 & 22 & 2 & 7 & 11 & 8 & 19 & 24 \\
5 & 22 & 7 & 19 & 16 & 23 & 2 & 8 & 24 & 18 & 11 \\
6 & 8 & 7 & 11 & 23 & 22 & 16 & 18 & 24 & 19 & 2 \\
7 & 8 & 7 & 11 & 23 & 22 & 16 & 18 & 24 & 19 & 2 \\
8 & 22 & 7 & 19 & 16 & 23 & 2 & 8 & 24 & 18 & 11 \\
9 & 18 & 19 & 2 & 8 & 23 & 24 & 11 & 16 & 22 & 7 \\
\hline
\end{tabular}

\subsection{Muhammad Iqbal research}

The study, titled "Prim's Algorithm for Optimizing Fiber Optic Trajectory Planning" discusses how to optimize fiber optic cabling. The price of the fiber optic cable is high, so it takes an algorithm that can determine the minimum length used for a particular area of the area. The author uses the Prim algorithm to perform the optimization process. Determining the number of cables manually is a difficult thing to do. The prim algorithm can help the analyst to determine the required cable length accurately. This algorithm works by calculating the minimum spanning tree in the area to be installed [45]. The algorithm also streamlines and accelerates the transmission of data from source to destination [21].

The researchers used 24 nodes in the minimum spanning tree track test. Some of the nodes are the circuit. A circuit is a condition where the nodes are connected in a circle. Several nodes are interconnected; it should be determined which node is shorter than others. Figure 3 is the sample of 24 nodes. 


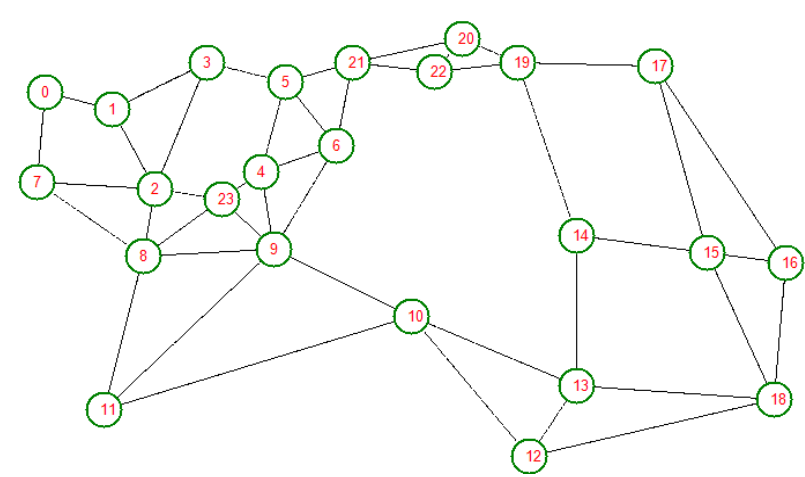

Fig. 3: Weighted Graph of Fiber Optic Installation.

Table 3 illustrates the location of the coordinates to which the fiber optic cable will be installed. Figure 4 is the result of the calculation of the Prim algorithm that produces the minimum spanning tree.

\begin{tabular}{llll} 
& \multicolumn{3}{c}{ Table 3: Graph Coodinate } \\
\hline No. & X & Y & Branches \\
\hline 0 & 22 & 29 & 1,7 \\
1 & 39 & 34 & $0,2,3$ \\
2 & 50 & 58 & $1,3,7,8,23$ \\
3 & 63 & 20 & $1,2,5$ \\
4 & 77 & 53 & $5,6,9,23$ \\
5 & 83 & 26 & $4,6,21$ \\
6 & 96 & 45 & $4,5,9,21$ \\
7 & 20 & 56 & $0,2,8$ \\
8 & 47 & 78 & $2,7,9,11,23$ \\
9 & 80 & 76 & $4,6,8,10,11,23$ \\
10 & 115 & 96 & $9,11,12,13$ \\
11 & 37 & 124 & $8,9,10$ \\
12 & 145 & 138 & $10,13,18$ \\
13 & 157 & 117 & $10,14,18$ \\
14 & 157 & 72 & $13,15,19$ \\
15 & 190 & 77 & $14,16,17,18$ \\
16 & 210 & 80 & $15,17,18$ \\
17 & 177 & 21 & $15,16,19$ \\
18 & 207 & 121 & $12,13,15,16$ \\
19 & 142 & 20 & $14,17,20,22$ \\
20 & 128 & 13 & $19,21,22$ \\
21 & 100 & 20 & $5,6,20,22$ \\
22 & 121 & 23 & 19,21 \\
23 & 67 & 61 & $2,4,8,9$ \\
\hline & & & \\
\hline
\end{tabular}

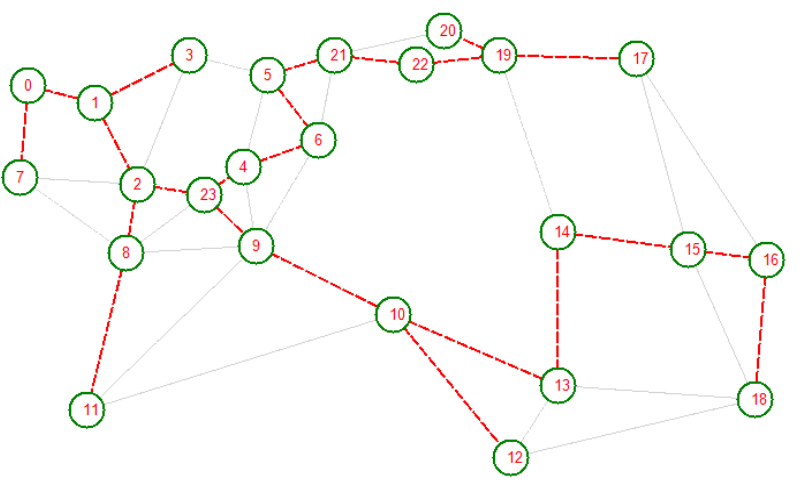

Fig. 4: Minimum Spanning Tree Result.

\section{Methodology}

This part is the design of graph formation. Some graph models will be created to test the ability of both algorithms in determining minimum spanning tree. The following image is the model graph used.

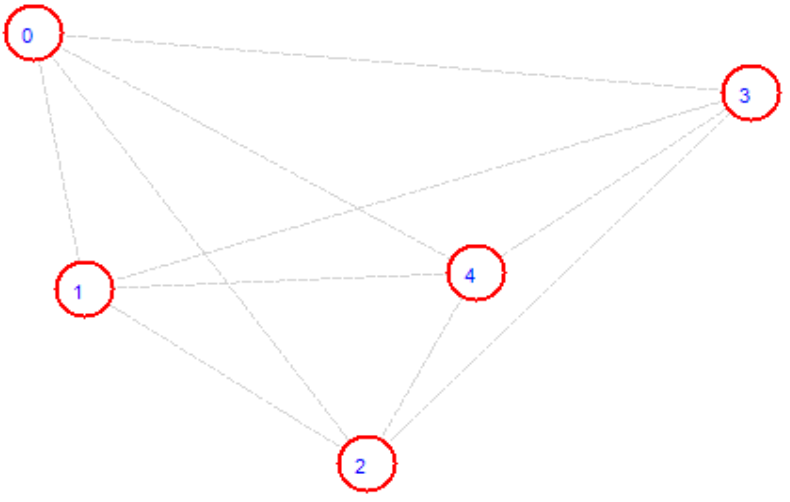

Fig. 5: Initial Graph Model.

Figure 5 describes five nodes connected to each other. Each node has different coordinate location as shown in the following table. Table 4 describes the position of the points described in Figure 5.

Table 4: Node Coordinate

\begin{tabular}{lll}
\hline Node & X & Y \\
\hline 0 & 38 & 29 \\
1 & 46 & 76 \\
2 & 90 & 108 \\
3 & 150 & 40 \\
4 & 107 & 73 \\
\hline
\end{tabular}

\section{Result and discussion}

Each node has a certain distance from another node. The distance calculation is obtained by using Euclidean Distance. The following illustration is the distance of each node.

Coordinate $[0]$ to Coordinate $[1]=47,68$

Coordinate [0] to Coordinate [2] $=94,58$

Coordinate $[0]$ to Coordinate $[3]=112,54$

Coordinate [0] to Coordinate [4] $=81,84$

Coordinate [1] to Coordinate $[0]=47,68$

Coordinate [1] to Coordinate [2] $=54,41$

Coordinate [1] to Coordinate [3] $=110,05$

Coordinate [1] to Coordinate $[4]=61,07$

Coordinate [2] to Coordinate [1] $=54,41$

Coordinate [2] to Coordinate [0] $=94,58$

Coordinate [2] to Coordinate [3] $=90,69$

Coordinate [2] to Coordinate [4] $=38,91$

Coordinate [3] to Coordinate [1] $=110,05$

Coordinate [3] to Coordinate [2] $=90,69$

Coordinate [3] to Coordinate $[0]=112,54$

Coordinate [3] to Coordinate [4] $=54,2$

Coordinate [4] to Coordinate [1] $=61,07$

Coordinate [4] to Coordinate [2] $=38,91$

Coordinate [4] to Coordinate [3] $=54,2$

Coordinate [4] to Coordinate [0] $=81,84$

The earlier calculation shows the distance values between nodes shown in the following figure. 


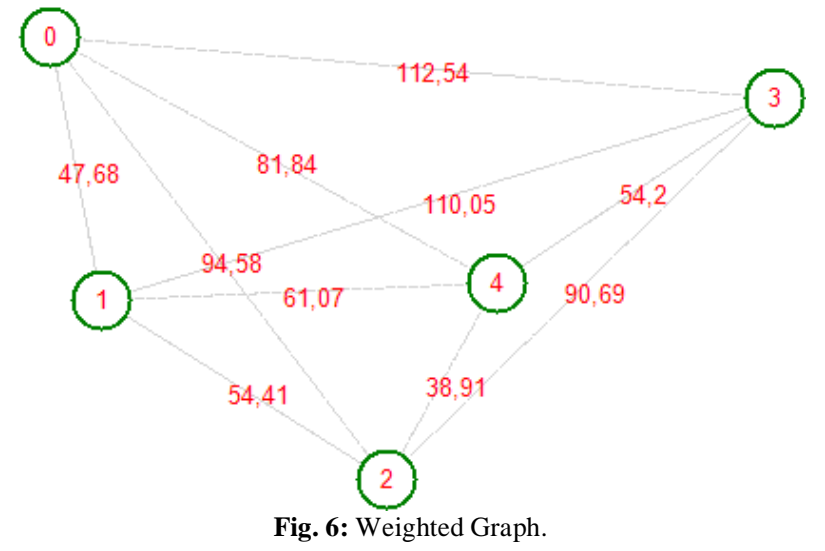

\subsection{Genetic algorithm test}

The test results using genetic algorithms always have different results on each test. It happens because the genetic algorithm uses random numbers as the population initialization and selection process. The random numbers generated are always different in each generation. Implementation of the genetic algorithm is not always successful. It needs multiple experiments to find the most optimal conditions. The following example is the first test using the genetic algorithm.

\section{Inital Population}

$\begin{array}{lllll}2 & 3 & 4 & 0 & 1 \\ 3 & 1 & 2 & 4 & 0 \\ 4 & 3 & 2 & 0 & 1 \\ 3 & 0 & 2 & 4 & 1 \\ 0 & 4 & 2 & 1 & 3\end{array}$

The test uses "Generation $=8 "$ and "Population $=5 "$. The final result can be seen in the following illustration.

\section{Generation $=8$}

$\begin{array}{lllll}4 & 2 & 0 & 1 & 3 \\ 1 & 0 & 4 & 2 & 3 \\ 1 & 0 & 4 & 2 & 3 \\ 1 & 0 & 4 & 2 & 3 \\ 0 & 1 & 3 & 4 & 2\end{array}$

\section{Fitness Calculation}

Population [0]

Distance : 203

Fitness : 0,00505050505050505

Population [1]

Distance :215

Fitness:0,00537634408602151

Population [2]

Distance: 215

Fitness : 0,00537634408602151

Population [3]

Distance : 215

Fitness: 0,00537634408602151

Population [4]

Distance: 298

Fitness: 0,00970873786407767

Population After Selection

$\begin{array}{lllll}4 & 2 & 0 & 1 & 3 \\ 1 & 0 & 4 & 2 & 3 \\ 1 & 0 & 4 & 2 & 3 \\ 0 & 1 & 3 & 4 & 2 \\ 1 & 0 & 4 & 2 & 3\end{array}$

Population After Mutation

$\begin{array}{lllll}4 & 2 & 0 & 1 & 3 \\ 2 & 1 & 3 & 4 & 0 \\ 4 & 1 & 3 & 2 & 0 \\ 0 & 3 & 1 & 4 & 2 \\ 2 & 1 & 3 & 4 & 0\end{array}$

Fitness After Elitism

Population [0]

Distance: 203

Fitness: 0,00505050505050505

Population [1]

Distance: 299

Fitness :0,00980392156862745

Population [2]

Distance : 290

Fitness: 0,00900900900900901

Population [3]

Distance: 307

Fitness:0,0106382978723404

Population [4]

Distance : 299

Fitness : 0,00980392156862745

Population After Elitism

$\begin{array}{lllll}4 & 2 & 0 & 1 & 3 \\ 2 & 1 & 3 & 4 & 0 \\ 4 & 1 & 3 & 2 & 0 \\ 0 & 3 & 1 & 4 & 2 \\ 2 & 1 & 3 & 4 & 0\end{array}$

The last generation shows the most optimum results for the whole generation and population. It is visible from the displayed list. Population [0] is the best value of the five populations. The route obtained is "4-2-0-1-3" which has a distance of 203 as shown in the following figure.

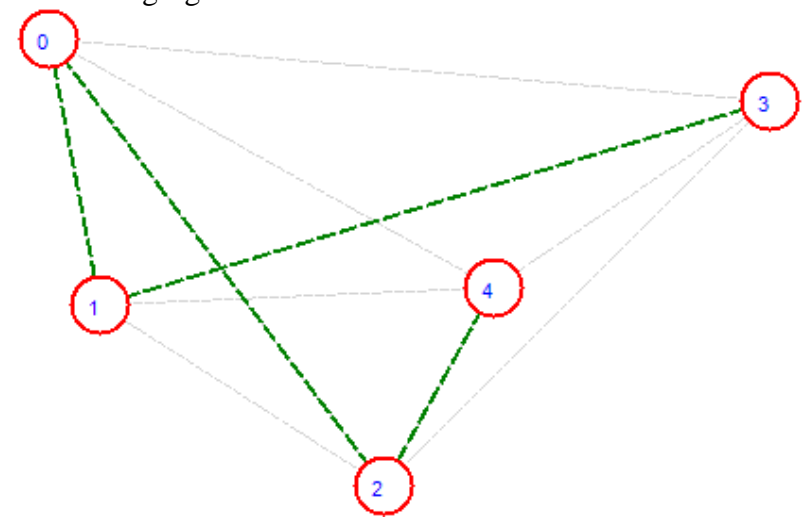

Fig. 7: Route of the First Test.

The following example is the second test using the genetic algorithm

Inital Population

$\begin{array}{lllll}3 & 1 & 0 & 4 & 2 \\ 3 & 1 & 0 & 4 & 2 \\ 2 & 4 & 3 & 0 & 1\end{array}$

The test uses "Generation $=3$ " and "Population $=3$ ". The final result can be seen in the following illustration.

Generation $=6$

$\begin{array}{lllll}4 & 1 & 0 & 2 & 3 \\ 0 & 2 & 4 & 1 & 3\end{array}$


$\begin{array}{lllll}0 & 2 & 4 & 1 & 3\end{array}$

Fitness Calculation

Population [0]

Distance: 207

Fitness:0,00515463917525773

Population [1]

Distance: 217

Fitness: 0,00543478260869565

Population [2]

Distance: 217

Fitness: 0,00543478260869565

Population After Selection

$\begin{array}{lllll}4 & 1 & 0 & 2 & 3 \\ 0 & 2 & 4 & 1 & 3 \\ 4 & 1 & 0 & 2 & 3\end{array}$

Population After Mutation

$\begin{array}{lllll}4 & 1 & 0 & 2 & 3 \\ 1 & 2 & 3 & 4 & 0 \\ 1 & 3 & 0 & 2 & 4\end{array}$

Fitness After Elitism

Population [0]

Distance :207

Fitness :0,00515463917525773

Population [1]

Distance :296

Fitness :0,00952380952380952

Population [2]

Distance :282

Fitness :0,00840336134453781

Population After Elitism

$\begin{array}{lllll}4 & 1 & 0 & 2 & 3 \\ 1 & 2 & 3 & 4 & 0 \\ 1 & 3 & 0 & 2 & 4\end{array}$

The last generation shows the most optimum results for the whole generation and population. It is visible from the displayed list. Population [0] is the best value of the five populations. The route obtained is "4-1-0-2-3" which has a distance of 207 as shown in the following figure. There are slightly different routes in the first and second experiments. In the first experiment, the route traversed was "4-2-0-1-3" while in the second experiment, the route traversed was "4-1-0-2-3".

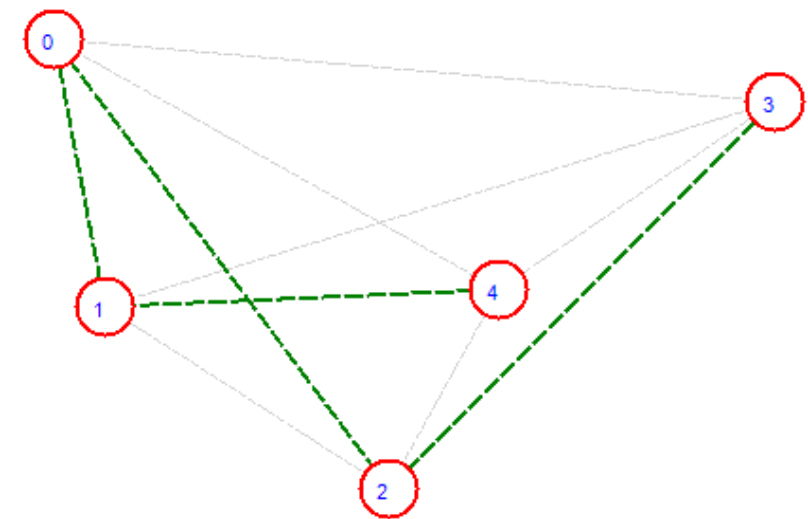

Fig. 8: Route of the Second Test.

The following example is the third test using the genetic algorithm Inital Population

$\begin{array}{lllll}4 & 1 & 0 & 2 & 3 \\ 2 & 0 & 3 & 4 & 1 \\ 2 & 3 & 1 & 0 & 4 \\ 4 & 2 & 0 & 1 & 3 \\ 1 & 3 & 0 & 2 & 4 \\ 4 & 2 & 1 & 0 & 3 \\ 1 & 0 & 3 & 4 & 2 \\ 3 & 2 & 4 & 1 & 0 \\ 4 & 2 & 1 & 0 & 3 \\ 1 & 2 & 0 & 3 & 4\end{array}$

The test uses "Generation $=20$ " and "Population $=10$ ". The final result can be seen in the following illustration.

Generation $=6$

$\begin{array}{lllll}3 & 1 & 0 & 2 & 4 \\ 2 & 1 & 0 & 4 & 3 \\ 4 & 3 & 2 & 0 & 1 \\ 3 & 0 & 4 & 1 & 2 \\ 3 & 0 & 2 & 1 & 4 \\ 3 & 4 & 1 & 0 & 2 \\ 4 & 3 & 2 & 0 & 1 \\ 0 & 1 & 4 & 3 & 2 \\ 4 & 2 & 0 & 3 & 1 \\ 3 & 0 & 4 & 1 & 2\end{array}$

Fitness Calculation

Population [0]

Distance : 203

Fitness : 0,00505050505050505

Population [1]

Distance : 216

Fitness : 0,00540540540540541

Population [2]

Distance : 277

Fitness : 0,00806451612903226

Population [3]

Distance : 225

Fitness : 0,00568181818181818

Population [4]

Distance :210

Fitness :0,00523560209424084

Population [5]

Distance : 211

Fitness : 0,00526315789473684

Population [6]

Distance : 277

Fitness : 0,00806451612903226

Population [7]

Distance : 302

Fitness : 0,0101010101010101

Population [8]

Distance : 282

Fitness : 0,00840336134453781

Population [9]

Distance :225

Fitness:0,00568181818181818

Population After Selection

$\begin{array}{lllll}3 & 1 & 0 & 2 & 4 \\ 4 & 3 & 2 & 0 & 1 \\ 3 & 0 & 4 & 1 & 2 \\ 2 & 1 & 0 & 4 & 3 \\ 4 & 2 & 0 & 3 & 1 \\ 3 & 4 & 1 & 0 & 2 \\ 0 & 1 & 4 & 3 & 2 \\ 4 & 2 & 0 & 3 & 1\end{array}$




$\begin{array}{lllll}4 & 3 & 2 & 0 & 1 \\ 4 & 3 & 2 & 0 & 1\end{array}$

Population After Mutation

$\begin{array}{lllll}3 & 1 & 0 & 2 & 4 \\ 0 & 3 & 2 & 4 & 1 \\ 3 & 2 & 0 & 1 & 4 \\ 3 & 1 & 2 & 4 & 0 \\ 4 & 3 & 2 & 1 & 0 \\ 0 & 1 & 4 & 3 & 2 \\ 0 & 4 & 1 & 2 & 3 \\ 4 & 3 & 2 & 1 & 0 \\ 3 & 2 & 1 & 0 & 4 \\ 3 & 2 & 1 & 0 & 4\end{array}$

Fitness After Elitism

Population [0]

Distance:203

Fitness :0,00505050505050505

Population [1]

Distance :304

Fitness :0,0103092783505155

Population [2]

Distance :207

Fitness :0,00515463917525773

Population [3]

Distance :222

Fitness :0,00558659217877095

Population [4]

Distance :292

Fitness :0,00917431192660551

Population [5]

Distance :302

Fitness :0,0101010101010101

Population [6]

Distance :226

Fitness :0,00571428571428571

Population [7]

Distance :292

Fitness :0,00917431192660551

Population [8]

Distance :212

Fitness :0,00529100529100529

Population [9]

Distance :212

Fitness : 0,00529100529100529

Population After Elitism

$\begin{array}{lllll}3 & 1 & 0 & 2 & 4 \\ 0 & 3 & 2 & 4 & 1 \\ 3 & 2 & 0 & 1 & 4 \\ 3 & 1 & 2 & 4 & 0 \\ 4 & 3 & 2 & 1 & 0 \\ 0 & 1 & 4 & 3 & 2 \\ 0 & 4 & 1 & 2 & 3 \\ 4 & 3 & 2 & 1 & 0 \\ 3 & 2 & 1 & 0 & 4 \\ 3 & 2 & 1 & 0 & 4\end{array}$

The last generation shows the most optimum results for the whole generation and population. It is visible from the displayed list. Population [0] is the best value of the five populations. The route obtained is "3-1-0-2-4" which has a distance of 203 as shown in the following figure. There are slightly different routes in the first, second and last experiments. In the first experiment, the route traversed was "4-2-0-1-3" while in the second experiment, the route traversed was "4-1-0-2-3", and the third is "3-1-0-2-4". There is no difference of route on first and third try. The results of these two experiments show that the optimum distance is 203 . However, both have differences at the beginning of the end of the route. It means that the most optimum value for a genetic algorithm can generate is 203. Although "Generation" and "Population" are extended to infinity, this will not create a more optimum value anymore.

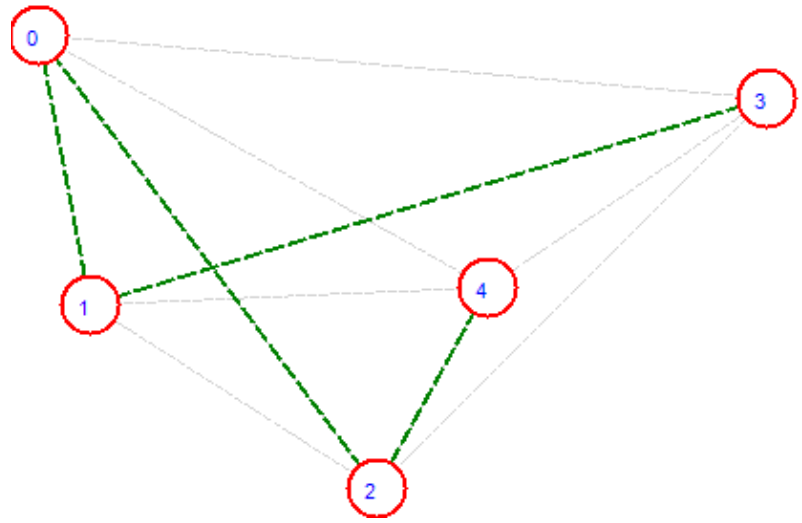

Fig. 9: Route of the Third Test

\subsection{Prim algorithm test}

This algorithm works greedily. If there are several nodes as an alternative, then the selected node is the shortest node from the beginning.

Table 5: Distance of Each Node

\begin{tabular}{llllll}
\hline \multicolumn{7}{c}{ Table 5: Distance of Each Node } \\
\hline N1 & 0 & N2 & N3 & N4 & N5 \\
N2 & 47.68 & 47.68 & 94.58 & 112.54 & 81.84 \\
N3 & 94.58 & 54.41 & 54.41 & 110.05 & 61.07 \\
N4 & 112.54 & 110.05 & 90.69 & 0 & 38.91 \\
N5 & 81.84 & 61.07 & 38.91 & 54.2 & 54.2 \\
\hline
\end{tabular}

The following table is the result of the calculation of Prim algorithm. The trip was made from N1 to N5. In N1, four possible nodes are the next destination. Each node will be compared where the distance of the node is the shortest from the beginning; the node is the next selected trip.

Table 6: Prim Algorithm Test Result

\begin{tabular}{llllll}
\multicolumn{5}{c}{ Table 6: Prim Algorithm Test Result } \\
\hline \multirow{2}{*}{ N1 } & \multirow{2}{*}{0} & N2 & 47.68 & 47.68 & \multirow{2}{*}{ N2 } \\
& & N3 & 94.58 & 112.54 & \\
& & N5 & 81.84 & & \\
& & N3 & 54.41 & & N3 \\
N2 & 0 & N4 & 110.05 & 54.41 & \\
& & N5 & 61.07 & & N5 \\
N3 & 0 & N4 & 90.69 & 38.91 & N4 \\
N5 & 0 & N5 & 38.91 & 54.2 & \\
\hline
\end{tabular}

The following figure is the result of graph formation based on the results obtained in the previous calculation.

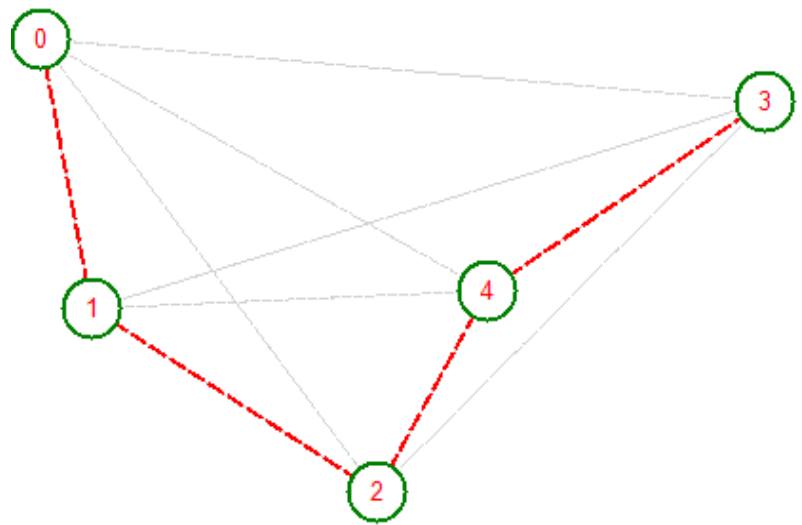


Fig. 10: Route of Prim Algorithm Test.

\section{Conclusion}

Prim and Genetic Algorithms can be used to optimize minimum spanning tree and travelling salesman problem. The fundamental difference is that the genetic algorithm cannot find the smallest distance as the Prim algorithm does. Another weakness of genetic algorithm is that crossover process cannot be done without changing the exchange system between parent and child. The genetic algorithm also can not do branching on the node as Prim does. It can determine the minimum weight of spanning tree maximal. This algorithm can also be used in the case of travelling salesman problems, but this requires little modification to route back to the starting point. The second test of this algorithm states that the Prim algorithm is better than Genetic algorithm because the minimum spanning tree process is a definite case. Genetic algorithms are better used for large cases that can not be done with brute-force techniques.

\section{References}

[1] S. Aryza, M. Irwanto, Z. Lubis, A. P. U. Siahaan, R. Rahim, and M Furqan, "A Novelty Design of Minimization of Electrical Losses in A Vector Controlled Induction Machine Drive," in IOP Conference Series: Materials Science and Engineering, 2018, vol. 300, no. 1.

[2] A. P. U. Siahaan et al., "Arduino Uno-based Water Turbidity Meter using LDR and LED Sensors,” Int. J. Eng. Technol., vol. 7, no. 4, pp. 2113-2117, 2018. https://doi.org/10.31227/osf.io/epkxs.

[3] I. B. A. I. Iswara et al., "Application of Data Encryption Standard and Lempel-Ziv-Welch Algorithm for File Security,” Int. J. Eng. Technol., vol. 7, no. 3.2, pp. 783-785, 2018.

[4] M. Putri, P. Wibowo, S. Aryza, A. P. U. Siahaan, and Rusiadi, "An Implementation of A Filter Design Passive LC In Reduce a Current Harmonisa," Int. J. Civ. Eng. Technol., vol. 9, no. 7, pp. 867-873, 2018.

[5] R. Rahim et al., "Combination Base64 Algorithm and EOF Technique for Steganography,” J. Phys. Conf. Ser., vol. 1007, no. 1, pp. 1-5, 2018. https://doi.org/10.1088/1742-6596/1007/1/012003.

[6] R. Meiyanti, A. Subandi, N. Fuqara, M. A. Budiman, and A. P. U. Siahaan, "The Recognition of Female Voice Based on Voice Registers in Singing Techniques in Real-Time using Hankel Transform Method and Macdonald Function,” J. Phys. Conf. Ser., vol. 978, no. 1, pp. 1-6, 2018. https://doi.org/10.1088/1742-6596/978/1/012051.

[7] A. P. U. Siahaan and R. Rahim, "Dynamic Key Matrix of Hill Cipher Using Genetic Algorithm," Int. J. Secur. It is Appl., vol. 10, no. 8, pp. 173-180, Aug. 2016

[8] A. Ikhwan, M. Yetri, Y. Syahra, and J. Halim, "A Novelty of Data Mining for Promoting Education based on FP-Growth Algorithm," Int. J. Civ. Eng. Technol., vol. 9, no. 7, pp. 1660-1669, 2018.

[9] Khairul et al., "Effect of Matrix Size in Affecting Noise Reduction Level of Filtering," Int. J. Eng. Technol., vol. 7, no. 3, pp. 1272 1275, 2018. https://doi.org/10.14419/ijet.v7i3.11333.

[10] R. Rahim et al., "Technique for Order of Preference by Similarity to Ideal Solution (TOPSIS) method for decision support system in top management," Int. J. Eng. Technol., vol. 7, no. 3.4, pp. 290 293, 2018.

[11] A. H. Lubis, S. Z. S. Idrus, and A. Sarji, "ICT Usage amongst Lecturers and Its Impact towards Learning Process Quality," vol. 34, no. 1, pp. 284-299, 2018.

[12] A. P. U. Siahaan, Rusiadi, P. L. E. Kan, K. N. F. K. Azir, and A Amir, "Prim and Genetic Algorithms Performance in Determining Optimum Route on Graph,” Int. J. Control Autom., vol. 11, no. 6, pp. 109-122, 2018.

[13] M. Townsend, Discrete Mathematic: Applied Combinatorics and Graph Theory. The Benjamin/Cummings Publishing Company, 1987.

[14] M. Negnevitsky, Artificial Intelligence: A Guide to Intelligent System. England: Addison-Wesley, 2005.

[15] A. P. U. Siahaan, "Heuristic Function Influence to the Global Optimum Value in Shortest Path Problem," IOSR J. Comput. Eng., vol. 18, no. 05, pp. 39-48, May 2016. https://doi.org/10.9790/06611805053948

[16] Z. Ramadhan, A. Putera Utama Siahaan, and M. Mesran, "Prim and Floyd-Warshall Comparative Algorithms in Shortest Path Prob- lem," in Proceedings of the Joint Workshop KO2PI and the first International Conference on Advance \& Scientific Innovation, 2018.

[17] V. N. S. Lestari, H. Djanggih, A. Aswari, N. Hipan, and A. P. U. Siahaan, "Technique for order preference by similarity to ideal solution as decision support method for determining employee performance of sales section," Int. J. Eng. Technol., vol. 7, no. 2.14 Special Issue 14, 2018.

[18] D. Kalpanadevi, "Effective Searching Shortest Path in Graph Using Prim's Algorithm," Int. J. Comput. Organ. Trends, vol. 3, no. 8, pp. 310-313, 2013

[19] A. P. U. Siahaan et al., "Combination of Levenshtein Distance and Rabin-Karp to Improve the Accuracy of Document Equivalence Level,” Int. J. Eng. Technol., vol. 7, no. 2.27, pp. 17-21, 2018.

[20] R. Rahim et al., "Prototype File Transfer Protocol Application for LAN and Wi-Fi Communication," Int. J. Eng. Technol., vol. 7, no. 2.13, pp. 345-347, 2018.

[21] M. Iqbal, A. P. U. Siahaan, N. E. Purba, and D. Purwanto, "Prim's Algorithm for Optimizing Fiber Optic Trajectory Planning," Int. J. Sci. Res. Sci. Technol., vol. 3, no. 6, pp. 504-509, 2017.

[22] C. Connolly, "Fibre-optic-based sensors bring new capabilities to structural monitoring," Sens. Rev., vol. 26, no. 3, pp. 236-243, Jul 2006. https://doi.org/10.1108/02602280610675537.

[23] T. Eddy, B. Alamsyah, S. Aryza, and A. P. U. Siahaan, "An Effect Phenomena Circle Living Field in Secanggang Langkat," Int. J. Civ. Eng. Technol., vol. 9, no. 7, pp. 1575-1580, 2018.

[24] W. S. Purba et al., "Relationships Among Knowledge, Attitude and Behavioral Intention of Waste Management Technology," Int. J. Civ. Eng. Technol., vol. 9, no. 9, pp. 792-798, 2018.

[25] S. Suroso et al., "Autoregression Vector Prediction on Banking Stock Return using CAPM Model Approach and Multi-Factor APT," Int. J. Civ. Eng. Technol., vol. 9, no. 9, pp. 1093-1103, 2018.

[26] A. Sanusi et al., "GCG SIMULTANEITY EFFECTS, PROFIT MANAGEMENT AND VALUE OF INDONESIAN RETAIL COMPANIES,” Int. J. Civ. Eng. Technol., vol. 9, no. 7, pp. 1506$1518,2018$.

[27] A. Sanusi et al., "Gravity Model Approach using Vector Autoregression in Indonesian Plywood Exports,” Int. J. Civ. Eng. Technol., vol. 9, no. 10, pp. 409-421, 2018.

[28] Rusiadi et al., "Dependence of poverty dependence on Indonesian economic fundamentals: Sfavar approach,” Int. J. Civ. Eng. Technol., vol. 9, no. 6, 2018 .

[29] A. I. F. Lubis et al., "Strategy for Improving Science and Welfare through Community Empowerment Technology," Int. J. Civ. Eng. Technol., vol. 9, no. 9, pp. 1036-1046, 2018.

[30] Rusiadi et al., "Simultaneous Response of Dividend Policy and Value of Indonesia Manufacturing Companies An Approach of Vector Autoregression," Int. J. Civ. Eng. Technol., vol. 9, no. 6, pp. 313-323, 2018.

[31] Rusiadi and A. Novalina, "Monetary Policy Transmission: Does Maintain the Price and Poverty Stability is Effective?" Jejak J. Ekon. dan Kebijak., vol. 11, no. 102, pp. 78-82, 2018.

[32] A. Novalina et al., "Confirmatory Factor Analysis Specimen in Calculating Independence Element of Coastal Woman,” Int. J. Civ. Eng. Technol., vol. 9, no. 9, pp. 1632-1644, 2018.

[33] Wikimedia, "Prim Algorithm," Wikimedia Commons, 2015. [Online]. Available: https://commons.wikimedia.org/wiki/File:Prim_Algorithm_1.svg.

[34] Z. Ramadhan, "Perbandingan Algoritma Prim dan Algoritma Floyd-Warshall dalam Menentukan Lintasan Terpendek (Shortest Path Problem)," Universitas Sumatera Utara, 2016.

[35] M. Furqan et al., "A Review of Prim and Genetic Algorithms in Finding and Determining Routes on Connected Weighted Graphs," Int. J. Civ. Eng. Technol., vol. 9, no. 9, pp. 1755-1765, 2018.

[36] S. Hartanto, M. Furqan, A. P. U. Siahaan, and W. Fitriani, "Haversine Method in Looking for the Nearest Masjid," Int. J. Recent Trends Eng. Res., vol. 3, no. 8, pp. 187-195, Aug. 2017. https://doi.org/10.23883/IJRTER.2017.3402.PD61H.

[37] R. Rahim et al., "Searching Process with Raita Algorithm and its Application," J. Phys. Conf. Ser., vol. 1007, no. 1, pp. 1-7, 2018. https://doi.org/10.1088/1742-6596/1007/1/012004.

[38] A. P. U. Siahaan, "Genetic Algorithm in Hill Cipher Encryption," Am. Int. J. Res. Sci. Technol. Eng. Math., vol. 15, no. 1, pp. 84-89, 2016.

[39] A. Philip, A. A. Taofiki, and O. Kehinde, "A Genetic Algorithm for Solving Travelling Salesman Problem," Int. J. Adv. Comput. Sci. Appl., vol. 2, no. 1, pp. 26-29, 2011.

[40] A. P. U. Siahaan, "Adjustable Knapsack in Travelling Salesman Problem Using Genetic Process,” Int. J. Sci. Technoledge, vol. 4, no. 9 , pp. $46-55,2016$ 
[41] S. Gupta and P. Panwar, "Solving Travelling Salesman Problem Using Genetic Algorithm," Int. J. Adv. Res. Comput. Sci. Softw. Eng., vol. 3, no. 6, pp. 376-380, 2013.

[42] H. Tabatabaee, "Solving the Traveling Salesman Problem using Genetic Algorithms with the New Evaluation Function," Bull. Environ. Pharmacol. Life Sci., vol. 4, no. 11, pp. 124-131, 2015.

[43] Y. F. Waruwu, "Analisis Nilai Mutasi Dinamis pada Algoritma Genetika," Universitas Sumatra Utara, 2016.

[44] Y. Deng, Y. Liu, and D. Zhou, “An Improved Genetic Algorithm with Initial Population Strategy for Symmetric TSP," Math. Probl. Eng., vol. 2015, pp. 1-6, 2015.

[45] Ş. B. Bozkurt and D. Bozkurt, "On the Number of Spanning Trees of Graphs," Sci. World J., vol. 2014, pp. 1-5, 2014. https://doi.org/10.1155/2014/294038. 